\title{
PUBLIC HEALTH CRISIS: THE NEED FOR PRIMARY PREVENTION IN FAILED AND FRAGILE STATES
}

\author{
John Quinn ${ }^{1}$, Preslava Stoeva², Tomáš Zelený ${ }^{3}$, Toozy Nanda', Alžběta Tomanová1, Vladimír Bencko³ \\ 'Prague Centre for Global Health, Institute of Hygiene and Epidemiology, First Faculty of Medicine, Charles University, Prague, Czech Republic \\ ${ }^{2}$ MSc Global Health Policy (DL), London School of Hygiene and Tropical Medicine, London, United Kingdom \\ ${ }^{3}$ Institute of Hygiene and Epidemiology, First Faculty of Medicine, Charles University, Prague, Czech Republic
}

\section{SUMMARY}

Objective: A new 'normal' in global affairs may be erupting from large global powers to that of non-state actors and proxies committing violence through scaled conflict in a post-Westphalian world generating significant global health policy challenges. Health security of populations are multifactorial and indirectly proportional to war, conflict and disaster. Preventing conflict and avoiding the health vacuum that occurs in war and violence may be best practices for policy makers. This paper considers an approach of applying clinical primary prevention principles to global health policy.

Methods: Brief policy review of current standards and practices in health security in fragile and failed states and prevention; and definitions discussion. A short case study series are presented with best practices, with risk and outcome review.

Results: The global balance of power and order may be shifting through geopolitical transference and inadequate action by major global power brokers. Health security in at risk nation-states may be decreasing as a result.

Conclusion: Small scale conflict with large-scale violence threatens health security and may experience increased incidence and prevalence in fragile and failed states. Preventative policy to resuscitate fragile and failed states and prevent further external and internal shocks may support health and promote a positive feedback loop of further state stability and increased health security. Public health policy shift to mitigate state failure and public health crisis in war and conflict through the basis of primary prevention may provide best practices and maximize health security for at risk populations.

Key words: fragile and failed states, infectious disease, non-communicable disease, primary prevention, evidenced based policy, health security

Address for correspondence: J. Quinn, Prague Centre for Global Health, Institute of Hygiene and Epidemiology, First Faculty of Medicine, Charles University, Studničkova 7, 12800 Prague 2, Czech Republic. E-mail: john.quinn@lf1.cuni.cz

https://doi.org/10.21101/cejph.a4671

\section{INTRODUCTION}

Violence, trauma, war, and conflict decrease the health security for communities. However, identifying links and determining causation remains a major challenge in the literature. Empirical studies focusing on direct retrospective data of states and the health of populations may offer a novel approach to the war and health challenge. Aggregate research has shown that health security diminishes in war, conflict, and failed and fragile states (1). This article discusses ways to reverse the decline and focuses on the case of failed and fragile states.

While there is no universally agreed definition of state failure, fragility and collapse, some indices and criteria have been proposed by global institutions, governments and academics (2). Some of these overlaps but do not align, feeding controversies over the meaning and exact parameters of state failure $(3,4)$. For the purposes of this article, we define as failed those states that have lost the ability to provide the most basic of services to their constituencies, and fragile as those on the brink of losing such ability $(5,6)$. Such services include functioning infrastructure and institutions that are expected to provide primary health services, prevention programmes along with key infrastructure that engenders health for the population.
The health security of populations living in fragile states requires provision of access to primary healthcare services that deliver disease and injury prevention, not just emergency care. Public health security is seen here as encompassing protection from environmental and behavioural health risks, basic protection against both communicable and noncommunicable diseases, as well as the provision of primary, secondary and tertiary prevention programmes.

In clinical medicine, primary prevention stops disease or injury before it starts; secondary prevention reduces the impact of disease or illness after the process has already begun; and tertiary prevention lessens the impact of a disease process already underway. Prevention programmes reduce morbidity and mortality. Prevention of disease saves lives, is immeasurably more cost efficient compared with treatment, and defines current best practices in public health. This article advocates prevention as an approach to global health policy for populations of decreased health security in fragile and failed state settings.

\section{Health Security in Failed and Fragile States}

The concept of health security is not consistently defined in the literature, its meaning being associated with human security, 
national and global public health security, securing and promoting the health of individuals and communities (7). Every one of these aspects is affected in failed and fragile settings. Fragile states experience a slow disappearance of state institutions and reduction in the rule of law, which brings about a deteriorating human and health security environment, destabilizes surrounding countries and encourages corruption and disrupts economic practice (8-10). Fragile and failed states have no safe, fair or legally regulated marketplace, leading to black-market economies and illegal arbitrage becoming widespread for basic goods, including health service provision.

When states experience fragility, failure or collapse, they cease to deliver basic human and health security or any level of public health. The government loses credibility, and the state becomes questionable and illegitimate in the hearts and minds of its citizens $(11,12)$. Fragile and failed states exhibit an increased propensity for conflict and violence, and a decreased ability to provide basic public health infrastructure to prevent, diagnose, provide adequate disease surveillance and combat infectious disease - leading to a significant decrease to health security (13-16). Figure 1 summarizes the contributing factors to state failure and the potential link to public health crisis.

Conflict and war have already been inextricably linked to the spread of disease and deterioration in health security $(13,17,18)$. Conflict threatens health security as it leads to an increase in infectious disease, preventable trauma, malnourishment, and mental health disorders $(9,19,20)$. Preventing state failure and conflict, therefore, can lead at least in part to increased health security. Policy highlights underscore patience of action - gradualism over short lived gains, and tailored responses that address specific state needs - not a panacea; but informed policy can enhance effective governance through a variety of models attuned to local patterns and needs, in advisory and supportive ways (21). Taking into account existing studies of the consequences of conflict and state fragility on health security along with empirical studies would provide a better foundation for such informed and evidenced based policy.

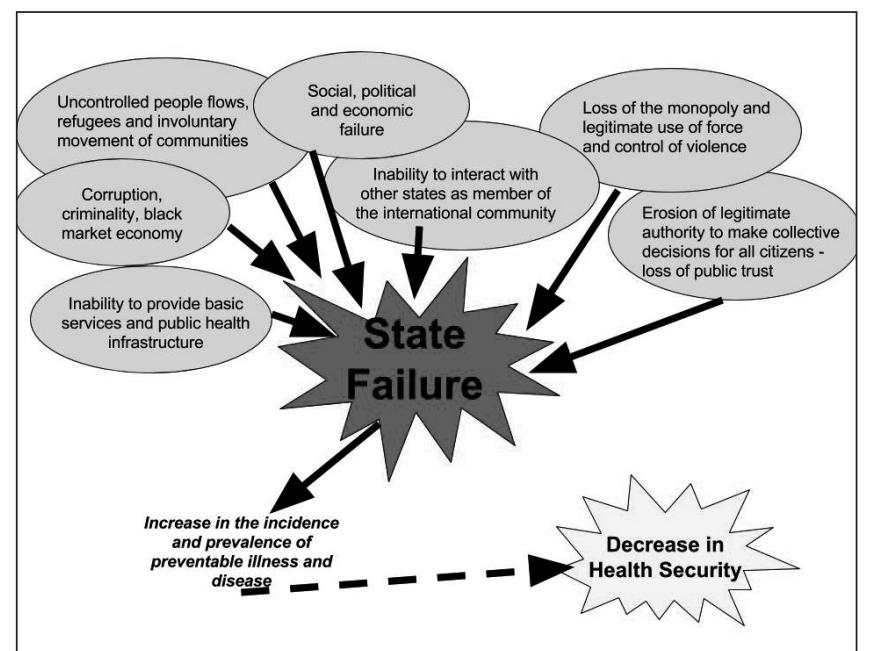

Fig. 1. Contributing factors to state failure and the potential link to health security and public health crisis.

\section{MATERIALS AND METHODS}

Current understandings of defining and promoting health security, along with key definitions of state failure and fragility, as well as clinical prevention, as an approach to health security policy are discussed in relation to the case studies of Ukraine and Syria and the challenge of a vaccine preventable disease. We implement these two case studies to assess the value of a policy of prevention, its potential benefits and drawbacks to health security and state stability.

Case studies in policy research and public health practice offer evidence, based on a specific set of variables and factors that can be tracked over a specific period of time with finite outcomes (22). The use of polio as the main research instrument yields the pathological sequelae of current warfare and instability and its effects on public health. Polio is vaccine preventable and had a greatly diminishing incidence and prevalence until recent conflict and state instability in places like Afghanistan, Pakistan, states affected by the Arab spring and more recently Ukraine. The use of polio as an indicator of health security in war in recent research has been accepted as a barometer of health systems $(23,24)$.

\section{RESULTS}

\section{Case 1: Ukraine}

\section{Background}

Former Ukrainian president Yanukovich's refusal to sign an agreement bringing Ukraine economically closer to the EU in November 2013 set off a political and social revolution. Following the unrest and the ousting of the president, the Crimean Peninsula was annexed violently by Russian forces. The two Regions of Donetsk and Luhansk were invaded and propped up through Russian backed separatists through de facto control of violence and body count just under 10,000 in late 2015 (25). There are currently areas within the Donetsk and Luhansk regions of Eastern Ukraine that are under Ukrainian government control and others that are not; Crimea is no longer under any Ukrainian control. Due to the conflict, basic services such as water, sanitation, hygiene, medical and primary health services, roads, and infrastructure are not consistently accessible or safe in at-risk government controlled areas or for many non-government controlled areas. Social and political systems of Ukraine prior to street protests calling for democratic reform were not well funded, but functioning at a basic level. Furthermore, healthcare systems in Donetsk and Luhansk (also referred to as 'Donbass') were performing very well for Ukraine. The revolution and conflict have destabilised these services, serving as a threat to the overall stability and legitimacy of the state.

\section{Health System Weakness}

The revolution has posed significant challenges to Ukraine's healthcare system. Over 5 million people are at risk of violence and over 1 million displaced. Paediatric and geriatric populations are most vulnerable to preventable illness. The Ukrainian health system was weak before the crisis and is now on the verge of collapse in areas affected by combat, areas with high Internally 
Displaced Peoples (IDP) loads, and regions requiring surge capacity and resilience to disruption of service delivery from the security crisis. About 30 to $70 \%$ of healthcare workers have fled the combat areas or died, healthcare provision has broken down and no supplies are available to replenish basic medical goods or vaccinations (26).

Due to the recent law that limits Ukraine's support to the Donbas region, many people living there are deprived of primary healthcare services. Comprehensive reports about civilian casualties from fighting are still pending for 2016 reporting, but since the beginning of the conflict in mid-April 2014 and until 19 February 2015, at least 5,793 people (including 63 children) were killed and 14,595 (including 169 children) were wounded in the East of Ukraine (27). The health system in Ukraine, in other words, has come under increasing strain within a deteriorating situation of state fragility, political tensions, and instability. This has had an effect on the delivery of primary prevention, which is discussed in the next section, with a specific focus on the status of polio vaccination programmes.

\section{Primary Prevention - the Case of Polio}

As a result of political instability, financial deficit, an ineffective and possibly corrupt procurement system at the Ministry of Health in Ukraine, the government tender process for procurement of vaccines for 2014 has not been fully implemented. Regional stocks of vaccines have already been exhausted. The average vaccination coverage in the country for some diseases is well under $40 \%$ (28). In some regions and communities most children have not been vaccinated at all since mid-2014. Given the large population displacement and the lowest immunization coverage in Europe, Ukraine remains at high risk of communicable disease outbreaks, especially among children. The WHO predicted that outbreaks of polio and measles were likely throughout the summer of 2015 . When in late summer 2015 positive cases of polio were identified with paralysed children, panic and humanitarian response were in crisis mode.

In an effort to bolster these needed vaccines, Sanofi-Pasteur has sent millions of Oral Polio vaccines for immediate use. However, the Ukrainian Council for Patient's Rights and Safety alleges these vaccines are unsafe due to cold chain management - alleging the frozen vaccines were partially thawed while in air transit to Ukraine from the manufacturer. Although the World Health Organisation (WHO) says the transport and refreezing were carried out in line with international best practice, the complaint alleges that the process contradicts a set of Ukrainian guidelines that state the vaccines cannot be refrozen. The outcome of their use is pending as of drafting of this paper. The at risk paediatric population awaits bureaucratic decision making and possibly corrupt practices.

\section{Discussion}

This short case study reveals the consequences of state instability and possibly state failure, demonstrating how it deteriorates health systems and healthcare infrastructure ultimately increasing morbidity and mortality from preventable diseases. Disruptions and shocks to public health infrastructure from state fragility and conflict have an effect not only on positive polio cases but increase the threat and risk of other vaccine preventable illness (both human and non-human transmission, i.e. tetanus). These continue to impact a shaky public health infrastructure in a fragile state and beg a broader question about the relationship between the health security of populations and state stability.

\section{Case 2: Syria}

\section{Background}

In late 2010, the Arab Spring erupted in Tunisia triggering a regional upheaval, social and political revolutions spanning North Africa and the Middle East. As old regimes were challenged or overturned in Tunisia, Algeria, Egypt, Libya, Lebanon, Jordan, Morocco, and Iran, Syria showed many signs of being next in line for democratic transition. As violence spread, multiple factions and groups took to the streets throughout the country and a civil war mushroomed into a major regional crisis. In the past 4 years of war, more than 250,000 people have died and more than 11 million have been displaced (29).

There has been international concern over the suspected use of chemical weapons, barrel munitions, and mass murder. There has been no official confirmation as to whether the Syrian state has carried out these attacks, or how other fighters may have retaliated but chemical weapons have been used and many have been killed (30). The Syrian state meets the criteria not only of state failure but also Zartman's criteria of state collapse where 'the structure, authority (legitimate power), law, and political order have fallen apart and must be reconstituted in some form, old or new' (31). It no longer controls core state functions, has little control over its territory, and has been unable to provide basic services and protection for its population since 2011-2012. The Russian Federation has recently (October 2015) committed to support the Syrian state by propping-up the Assad's regime at all costs (32). However, based on the past 5 years of the Assad's policy focus of centralizing power, it is unclear if it would be able to make good on any state based basic services, healthcare infrastructure provisions or other measures that promote health security at least in the near future.

\section{Health System Collapse}

In mid-October 2015, over 35,000 people became displaced in Hama as result of a renewed government offensive supported by Russian airstrikes (33). It is possible that external and internal shocks from the Islamic State in Iraq and the Levant (ISIS/ISIL) have fomented and exacerbated the crisis, leaving in its wake no access to any healthcare services for millions of people. The UN Office for Coordination of Humanitarian Affairs (OCHA) and UNHCR estimated that 'by mid-2014 10.8 million of Syria's population was affected by the conflict and in need of humanitarian assistance, including 6.5 million internally displaced persons' (34). The European Commission reports that 'the long-lasting consequences of the conflict with shortages of qualified medical personnel and life-saving medicines, and the destruction of health infrastructure have left many (in Syria) without access to basic medical care. In effect, the Syrian healthcare apparatus is defunct and no longer providing for its people.

Medical facilities continue to be targeted by aerial bombardments, resulting in fatalities and destruction of facilities. Delivery of essential medical supplies and equipment, especially in opposition-controlled areas, is often blocked and the provision 
of aid to besieged and hard-to-reach areas is particularly difficult' (33). With Russian backed bombing campaigns against multiple targets in Syria, coalition-backed aerial bombing against ISIS/ ISIL targets in Syria and Iraq, the delivery of humanitarian aid and basic health services remain under great threat.

\section{Primary Prevention - the Case of Polio}

Political instability and conflict has disrupted the public health infrastructure in Syria, including paediatric access to primary healthcare and has blocked routine vaccines for millions. Routine vaccines (e.g. polio, tetanus and measles, mumps and rubella and others) have not been administered to many communities and populations at risk. In late October 2013, over 10 cases of polio were confirmed, followed by another 14 in early 2014 and 20 for the rest of the year, with paralysis of one patient in late December 2014 (23). Prior to the current outbreak, Syria's last confirmed polio case was in 1999. Syria had remained polio-free until October 2013 when wild poliovirus was confirmed in Deir ez-Zor and Aleppo (35). The rapid growth in cases coincides with the continuing period of turmoil and violence, demonstrating a causal relationship between state failure and the lack of provision of primary healthcare and prevention, which has also become a source of health insecurity.

\section{Discussion}

The case studies of Ukraine and Syria demonstrate how different two situations can be while still falling in the same broad category of state fragility and failure. These two cases illustrate the relationship between political instability and the weakness or failure of health systems and the delivery of health services. It has already been documented that conflict increases the strain on health services, but here we demonstrated that the latter are also challenged by the inability of governments to exercise effective authority and control over the territory and population of their state.

While international responses to state fragility have been limited, they have tended to focus on the delivery of emergency care. Conflict and state fragility, however, affect the infrastructure that enables the provision of routine health services. Polio immunisation is taken here as a research instrument through two case studies to illustrate how failure in the provision of routine health services in fragile state settings has long term consequences. What empirical research has found in comparing these two current situations of internal conflict combined with state fragility, is that two similar situations have had different outcomes. The incidence of polio in Syria is larger than that in Ukraine on a real number basis. We believe these differences are due to two main factors - the condition and strength of the health system prior to the situation of conflict and fragility and to the intensity of the conflict itself, which further hinders health services provision. A stronger Ukrainian health system prior to conflict may have a higher compliance to vaccination and primary prevention programmes leading to a larger herd immunity effect, protecting more at risk non-vaccinated individuals.

International responses to crisis and disasters should focus not only on emergency medical support, but also on the provision of routine primary prevention. In political terms, the international community should pursue the goal of preventing state failure and the resuscitation of failed states, so as to engender an environment for transparent and accountable health related institutions and maximize health care outcomes - directly benefitting the populations they serve. This can include primary prevention in the form of primary healthcare services to the paediatric population with basic and advanced vaccination programmes; secondary prevention for non-communicable diseases in the form of screening for middle aged and geriatric patients that may have diabetes, hypertension, cardiovascular disease, cancer, and many others; and finally tertiary prevention, mitigating all of the above from causing further health status decline across all patient populations through medical care, education and lifestyle changes. Preventing war, conflict and violence will increase health security; these factors may also be affected by preventing state failure.

The prevention concepts listed above are not a policy of action that can be perverted to defend invasion, control of violence from one state to another or more killing. Rather, a policy of prevention, rooted in best practices and evidence-based policy, must be a gradual process that stable states offer to fragile states through patient, long-term, mostly advisory and humanitarian aid relationships. Possibly based on such activities as direct economic assistance focused on local needs; training of civil staff, academic and governmental exchanges, and other human-capacity development programmes; military-to-military ties (M2M) that deconflict previous emphasis on destruction and instead on disaster risk reduction; trade and investment policies that reduce exploitation - all reinforcing the state and creating an environment for improved healthcare provision. Early warning systems that focus on metrics associated with fragile and failed states should indicate states' status on the continuum of fragility and failure in order to assist and support donors, from the public and private aid community in prioritizing policy focus (36).

\section{Limitations}

This short case study approach to complex issues such as health security, global affairs and preventable illness is limited by the amount of data reviewed. Case studies for preventable illness of polio in war and conflicted states may not be the best marker or indicator for health of a population. Data related to population titres and seroconversion rates of selected preventable illness may prove to be a more robust and powerful study in relating state stability to health. Clearly, these topics are insufficiently studied and reported in the literature. This question about the relationship between health security and state security is both fascinating and underexplored. Linkages of state and health and the question of causality, (i.e. does it flow from state to individual, individual to state or is the process more complex?) are yet to be described or answered. More detailed relationships of health and state stability can better describe these potentially causal relationships.

\section{CONCLUSION}

Mitigating state failure and reviving fragile states must become a key policy objective for development and public health programming for states in crisis - fragile states are not preordained to state failure or absolute collapse. Failed states, conflict and health security are linked. Small scale conflict and large scale violence 
both threaten public health security. Health security can be gained in part through primary health care access and vaccination and prevention programmes.

Country-specific approaches to encourage the rule of law, transparent and representative institutions, to limit state controlled violence, and foster environmental integrity must comprise any political action. Such efforts are best delivered via concerted international efforts - including programmes by intergovernmental institutions, the International Committee of the Red Cross (ICRC), humanitarian agencies, civil society organisations and other donors - rather than by means of sovereign states intervening militarily in other sovereign states. Preventing public health crisis in fragile and failed states through a policy of prevention ought to incorporate the provision of adequate food, sustainable shelter, water, sanitation, adequate vaccination programmes, and access to primary healthcare services $(37,38)$.

Failed or failing states are likely to present complex political and security situations, defined by a high degree of instability and risk of violence. Since degrees of instability and state control over civil strife situations may vary, other ways need to be established to provide preventative health services in order to guarantee the right to health to all people.

\section{Acknowledgements}

The authors acknowledge their thanks to the 1st Faculty of Medicine, Charles University in Prague, the Institute of Economic Studies at Faculty of Social Sciences of Charles University in Prague and to the Department of Global Health and Development at the London School of Hygiene and Tropical Medicine for their support of this research. We also wish to thank Prof. Noam Chomsky for his correspondence and guidance with some of the underlying concepts behind the paper. This paper was supported by grants GAUK 910892 and PRVOUK- P28/1LF/6 to produce the final product.

\section{Conflict of Interests}

None declared

\section{REFERENCES}

1. Quinn J, Zelený T, Subramaniam R, Bencko V. Public health crisis in war and conflict: health security in aggregate. Cent Eur J Public Health. 2017 Mar;25(1):72-6.

2. Messner JJ. The failed states index. Foreign Policy. 2005;149:56-65.

3. Kraxberger BM. Failed states: temporary obstacles to democratic diffusion or fundamental holes in the world political map? Third World Quarterly. 2007;28(6):1055-71.

4. Patrick S. "Failed" states and global security: empirical questions and policy dilemmas. International Studies Review. 2007;9(4):644-62.

5. Quinn J, Martins N, Cunha M, Higuchi M, Murphy D, Bencko V. Fragile states, infectious disease and health security: the case for Timor-Leste. J Hum Secur. 2014;10(1):14-31. doi: 10.12924/johs2014.10010014.

6. Bencko V, Quinn J. Environmental risk and risk perception management in public health. Health. 2013;5(3):440-4

7. Aldis W. Health security as a public health concept: a critical analysis. Health Policy Plan. 2008 Nov;23(6):369-75.

8. Naim M. Illicit: how smugglers, traffickers and copycats are hijacking the global economy. Doubleday Press; 2006.

9. Quinn J, Zeleny T, Bencko V. Food is security: the nexus of health security in fragile and failed states. Food Nutr Sci. 2014 Oct;5(19):1828-42.

10. Zartman IW. Cowardly lions: missed opportunities to prevent deadly conflict and state collapse. London, UK: Lynne Rienner Publishers; 2005.
11. Rotberg RI. When states fail: causes and consequences. Princeton, USA: Princeton University Press; 2004.

12. Messner JJ, editor. The Failed States Index 2011. Washington: The Fund for Peace; 2011.

13. Ottaway M, Mair S. States at risk and failed states - putting security first. Democracy \& Rule of Law Project. German Institute for International and Security Affairs, Carnegie Endowment for International Peace; 2004.

14. Frieden TR, Henning KJ. Public health requirements for rapid progress in global health. Glob Public Health. 2009;4(4):323-37.

15. Mallaby S. The reluctant imperialist: terrorism, failed states, and the case for American Empire. Foreign Affairs [Internet]. 2002 Mar [cited 2012 Mar 1]. Available from: https://www.foreignaffairs.com/articles/ united-states/2002-03-01/reluctant-imperialist-terrorism-failed-statesand-case-american.

16. Patrick S. Weak states and global threats: assessing evidence of spillovers. Working paper no. 73 [Internet]. Center for Global Development; 2006 [cited 2016 Aug 11]. Available from: https://www.cgdev.org/ files/5539_file_WP_73.pdf.

17. Helman GB, Ratner SR. Saving failed states: how the United Nations let countries fall apart, and how it needs to adapt if it wants to put them back together. Foreign Policy. 1992-1993;89:3-20.

18. Lyon $P$. The rise and fall and possible revival of international trusteeship. Journal of Commonwealth and Comparative Politics. 1993;31(1):96-110.

19. Collier P. The bottom billion: why the poorest countries are failing and what can be done about it. Oxford: Oxford University Press; 2007.

20. Hotez PJ. Forgotten people, forgotten diseases: the neglected tropical diseases and their impact on global health and development. Washington, DC: American Society for Microbilogy Press; 2008.

21. Mazarr MJ. The rise and fall of the failed-state paradigm: requiem for a decade of distraction. Foreign Affairs [Internet]. 2014 Jan/Feb [cited 2016 Mar 30]. Available from: https://www.foreignaffairs.com/articles/2013-12-06/rise-and-fall-failed-state-paradigm.

22. Ulin PR, Robinson ET, Tolley EE. Qualitative methods in public health: a field guide for applied research. New York: Jossey-Bass; 2012.

23. Garon JR, Orenstein WA. Overcoming barriers to polio eradication in conflict areas. Lancet Infect Dis. 2015 Oct;15(10):1122-4.

24. Obradovic Z, Balta S, Obradovic A, Mesic S. The impact of war on vaccine preventable diseases. Mater Sociomed. 2014 Dec;26(6):382-4.

25. Manzi B, Tashtankulov A, Abou Hamra A, Morland J. Humanitarian Bulletin Ukraine. 2015 Oct 1-31;(3).

26. Quinn J. Notes from the field: the humanitarian crisis in Ukraine. Journal of Human Security. 2015;11(1):27-33. doi:10.12924/johs2015.11010027.

27. United Nations Office for the Coordination of Humanitarian Affairs. Ukraine. Situation report No. 28 [Internet]. OCHA; 2015 [cited 2016 Mar 30]. Available from: http://reliefweb.int/sites/reliefweb.int/files/ resources/Sitrep\%20\%2328-\%20FINAL.pdf.

28. Holt E. Health care collapsing amid fighting in east Ukraine. Lancet. 2015 Feb 7;385(9967):494.

29. United Nations High Commissioner for Refugees (UNHCR). Syria in Focus. 2015;(13).

30. Pita R, Domingo J. The use of chemical weapons in the Syrian conflict. Toxics. 2014;2(3):391-402.

31. Zartman IW. Introduction: posing the problem of state collapse. In: Zartman IW, editor. Collapsed states: the disintegration and restoration of legitimate authority. Boulder, CO: Lynne Rienner Publishers; 1995: p. 1.

32. Adamsky D. Putin's Syria Strategy. Foreign Affairs [Internet]. 2015 Oct 1 [cited 2016 Mar 30]. Available from: https://www.foreignaffairs.com/ articles/syria/2015-10-01/putins-syria-strategy.

33. European Commission. European Civil Protection and Humanitarian Aid Operations. Syrian crisis [Internet]. ECHO; 2015 [cited 2015 Nov 28]. Available from: http://ec.europa.eu/echo/files/aid/countries/factsheets/ syria_en.pdf.

34. UNHCR.org [Internet]. The United Nations Refugee Agency (UNHCR). [cited 2015 Nov 28]. Available from: http://www.unhcr.org/ pages/49e486a76.html.

35. World Health Organization. Polio Eradication Initiative: Syrian Arab Republic [Internet]. Geneva: WHO [cited 2015 Nov 24]. Available from: http://www.emro.who.int/polio/countries/syrian-arab-republic.html.

36. Baliamoune-Lutz M, McGillivary M. State fragility: concept and measurement. Research paper no. 2008/44. World Institute for Development Economic Research (UNU-WIDER); 2008.

37. Davies JL, Gurr TR, editors. Preventive measures: building risk assessment and crisis early warning systems. Lanham, MD: Rowman \& Littlefield; 1998 
38. Toole MJ, Waldman RJ, Zwi AB. Complex humanitarian emergencies. In: Merson M, Black R, Mills A, editors. International public health: diseases, programs, systems, and policies. 2nd ed. Sudbury, MA: Jones \& Bartlett; 2006. p. 445-511. 